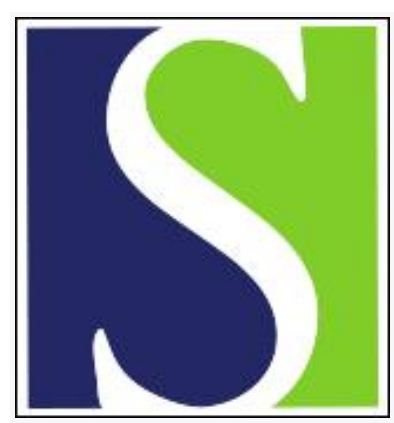

Scand J Work Environ Health 1986;12(5):461-468

https://doi.org/10.5271/sjweh.2111

Issue date: Oct 1986

Exposure to formaldehyde and cancer mortality in a cohort of workers producing resins.

by Bertazzi PA, Pesatori AC, Radice L, Zocchetti C, Vai T

This article in PubMed: www.ncbi.nlm.nih.gov/pubmed/3787218

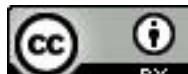




\title{
Exposure to formaldehyde and cancer mortality in a cohort of workers producing resins
}

\author{
by Pier A Bertazzi, MD, Angela C Pesatori, MD, Laura Radice, MD, Carlo Zocchetti, ScD, \\ Tiziana Vai, MD ${ }^{1}$
}

\begin{abstract}
BERTAZZI PA, PESATORI AC, RADICE L, ZOCCHETTI C, VAI T. Exposure to formaldehyde and cancer mortality in a cohort of workers producing resins. Scand $J$ Work Environ Health 12 (1986) 461-468. The mortality of 1332 male workers employed at least 30 days in 1959-1980 in a resins-manufacturing plant was examined. Ambient measurements taken in the plant between 1974 and 1979 documented a potential for exposure to levels of formaldehyde as high as $\geq 3.0 \mathrm{mg} / \mathrm{m}^{3}$. Vital status was ascertained for $98.6 \%$ of the cohort members, and their mortality was compared with expected deaths drawn from the national and local population rates. A statistically significant increase in lung cancer was observed, based on 18 deaths, which was not fully accounted for by possible confounding factors linked to personal habits or sociocultural characteristics. This elevated risk, however, could not be attributed specifically to exposure to formaldehyde. Mortality from digestive cancer (14 deaths observed) and hematologic neoplasms ( 5 deaths observed) was not substantially higher than expected. The study was limited by information bias due to incomplete work histories, by the small number of deaths from some relevant causes, and by the possibly insufficient length of the observation period. Therefore these results do not provide sufficient grounds either to link formaldehyde exposure in the plant to the increased cancer risk noted or to exclude that formaldehyde might pose such a risk to humans under certain exposure circumstances.
\end{abstract}

Key terms: information bias, lung cancer, occupational cancer, occupational epidemiology.

Formaldehyde (HCHO) is an almost ubiquitous compound in the natural and man-made environment, and a normal metabolic product in most life forms. Its chemical identification and preparation dates back to the middle of the past century. The estimated current worldwide volume of formaldehyde as a commodity chemical is over 4.5 million tons per year. Exposure to formaldehyde has been documented in a large variety of industrial settings, ranging from medical and laboratory environments to agriculture and wood, plywood and particle board, textile, and paper industries. In the chemical industry, exposure to formaldehyde occurs in rubber and explosives manufacturing, tanning, dying, etc; the major (and increasing) use is in plastics production (eg, urea-, phenol-, and melamine-formaldehyde resins) (9).

Adverse health effects on the human respiratory tract and the skin associated with exposure to formaldehyde have been reported for a rather long time (5, 15). Recently, results of experimental inhalation studies performed in different laboratories showed that formaldehyde was carcinogenic. Squamous cell carcinomas of the nasal cavity were induced in mice and rats with a sharp dose-response relationship $(3,12)$. Such reports prompted new investigations on the long-term effects possibly associated with human exposure to formaldehyde. Epidemiologic studies were carried out in

1 Institute of Occupational Health "Clinica del Lavoro L Devoto," University of Milan, Milan, Italy.

Reprint requests to: Dr PA Bertazzi, Istituto di Medicina del Lavoro, Universita' degli Studi, Via San Barnaba 8, I-20122 Milano, Italy. various occupationally exposed populations. Different designs were used, ie, proportional mortality ratio (PMR) studies $(14,16,20,22)$, standardized mortality ratio (SMR) studies $(1,7,8,13,23)$, and case-referent studies $(4,11,17,18)$. Their results have been inconclusive so far. Case reports have also been published which yielded contrasting results $(6,10)$.

Given such background, further epidemiologic research seemed fully justified. This study was initiated upon a joint request of the management and unions of a plant manufacturing resins, where a reportedly high number of cancer deaths had occurred in recent years. The study was designed as a cohort mortality investigation covering the period from the beginning of production up to the end of 1980 . Although the period of time elapsed from the beginning of production of formaldehyde-based resins was perhaps not sufficiently long (22 years) and the exposed population not very large, still the study seemed worth conducting as, according to historical environmental data, the potential for human exposure to formaldehyde in similar occupational settings was among the highest (9).

\section{Subjects and methods}

\section{Plant description and exposure}

The plant had been manufacturing different types of resins for varying periods of time, starting in 1959. The sole production constantly carried on, and the largest, had been that of urea- and melamine-formaldehyde resins. According to the workers and plant technicians, 
there was, at least in past years, a continuous pungent odor of formaldehyde in the ambient air of the area where formaldehyde-based resins were produced during the entire workshift. The olfactory threshold for formaldehyde is $0.05 \mathrm{ppm}$, and mild irritating symptoms have been described in association with a wide range of airborne concentrations (from 0.1 to several parts per million) depending on the duration of exposure (5). The second largest production was styrenebased resins (polystyrene and copolymers). A third, and much more limited, production involving a potential for exposure to a suspected carcinogen (epichlorohydrin) was epoxy resins. Other resins manufactured in the plant were polyesters and colophony resins. Each type of production occurred in a separat $\epsilon$ building, with the exception of epoxy and colophony resins. In several production areas there was a potential for exposure to various solvents, eg, xylene, toluene, methyl isobutyl ketone, etc.

Few environmental measurements of airborne contaminants had been taken between 1974 and 1979. Table 1 presents the formaldehyde results, which were judged by plant technicians as "typical" ambient air concentrations in those years. Technological changes and improvements of the production processes were undertaken only after 1975. It is reasonable, then, to assume that, in preceding years, exposure to the mentioned compounds had been even higher.

\section{Study population and follow-up}

All male workers ever employed in the plant at any time and in any department between 1959 and 1980 for a period of at least 30 days were considered eligible for the study. Meeting these criteria were 1332

Table 1. Airborne concentration of formaldehyde (fixed area samples) at different times in the plant section where formaldehyde-based resins were manufactured $\left(1.5 \mathrm{mg} / \mathrm{m}^{3}=1.0\right.$ ppm).

\begin{tabular}{lccc}
\hline $\begin{array}{l}\text { Date of } \\
\text { sampling }\end{array}$ & $\begin{array}{c}\text { Number of } \\
\text { samples }\end{array}$ & $\begin{array}{c}\text { Mean value } \\
\left(\mathrm{mg} / \mathrm{m}^{3}\right)\end{array}$ & $\begin{array}{c}\text { Maximum value } \\
\left(\mathrm{mg} / \mathrm{m}^{3}\right)\end{array}$ \\
\hline July 1974 & 3 & 3.3 & 4.3 \\
November 1978 & 12 & 1.3 & 2.5 \\
& 12 & 0.3 & 0.5 \\
December 1978 & 12 & 0.6 & 1.4 \\
January 1979 & 12 & 0.2 & 0.5 \\
& 12 & 0.5 & 1.0 \\
& 12 & 1.5 & 2.5 \\
February 1979 & 12 & 0.7 & 1.1 \\
& 12 & 0.6 & 1.0 \\
& 12 & 1.9 & 3.7 \\
& 12 & 1.0 & 1.2 \\
March 1979 & 3 & 2.7 & 5.0 \\
April 1979 & 12 & 3.6 & 4.1 \\
May 1979 & 3 & 2.6 & 9.8 \\
\hline
\end{tabular}

workers. Their vital status was ascertained as of 31 December 1980 . There were 350 workers still active in the factory at the beginning of the study. For former employees, vital status was ascertained through the vital statistics offices of the places where they resided or were born. For all deceased subjects death certificates were obtained from the same source.

For each worker the plant Personnel Office was able to supply (besides personal data such as name, residence, date of birth, etc) only the date of hire and date of resignation. Specific jobs held in the plant were comprehensively recorded only for current employees. Reconstruction of work history for past employees was thus attempted in interviews of retired workers still living in the area, current workers employed for a long time, and foremen. A work history was considered acceptable only after the data were double-checked with the Personnel Office, which provided information according to its best knowledge and the existing, although incomplete, records. In this way, work histories were collected for all but $18 \%$ of the workers in the study.

The fixed area measurements available could not be used for estimating the job-specific exposure of individual workers, either because of their very nature (area samples) or because of their limited number.

Notwithstanding the limited information, workers were subdivided into the following three exposure categories: "exposed to formaldehyde," "exposed to other compounds," "'exposure unknown." Apart from the group with unknown exposure, the classification of workers according to their having or having not been operating in jobs with exposure to formaldehyde was considered acceptable for the study purposes, thanks to the fact that the job mobility in the plant turned out to have been rather low. As a matter of fact, $79 \%$ of the workers in the study had been employed in a single job during their career in the plant, and almost all workers engaged in the formaldehyde-based resins production had not spent relevant periods of time in other departments.

\section{Analysis}

The information collected was analyzed with a computer program specifically developed for cohort studies (24). Each subject contributed to the person-year calculation from the day he reached the minimum defined exposure period ( 30 days) until the end of the study (31 December 1980) or, if deceased, until the date of death. Expected deaths were calculated from two sets of mortality rates (national and local) specific by cause, sex, age (five years), and calendar time (five years). Local rates were used in an attempt to control at least for the major, possibly confounding, social, cultural, and geographic factors. The ratios of observed to expected deaths x 100 (SMR) were then calculated. Fisher exact confidence limits were computed on the assumption of a Poisson distribution for the observed deaths, 
with published desk calculator programs (19). SMR values were also employed to compare mortality across the three subcohorts with different exposure, although the person-years distributions were somehow different. From figure 1, one can note that workers exposed to formaldehyde were, on the average, a little older but, in our judgement, not enough so as to invalidate the analysis. The comparison carried out after the direct standardization of the rates supported this view.

\section{Results}

The follow-up was successful for $98.6 \%$ of the study population, and 112 workers had died during the study period (table 2). A total of 20336 person-years of observation were accumulated.

The comparison of workers' mortality from selected causes with the expected figures drawn from the national and local rates yielded the results shown in table 3. A changing pattern of the observed: expected ratios is apparent, depending on which set of rates was

Table 2. Results of the follow-up of a cohort of workers manufacturing resins as of 31 December 1980.

\begin{tabular}{lcc}
\hline Status & Number & Percentage \\
\hline Admitted & 1332 & 100.0 \\
Traced & 1314 & \\
Alive & 1202 & 90.2 \\
Dead & 112 & 8.4 \\
Not traced & 18 & 1.4 \\
\hline
\end{tabular}

used in calculating the expected number of deaths. The overall mortality did not depart significantly from ex-

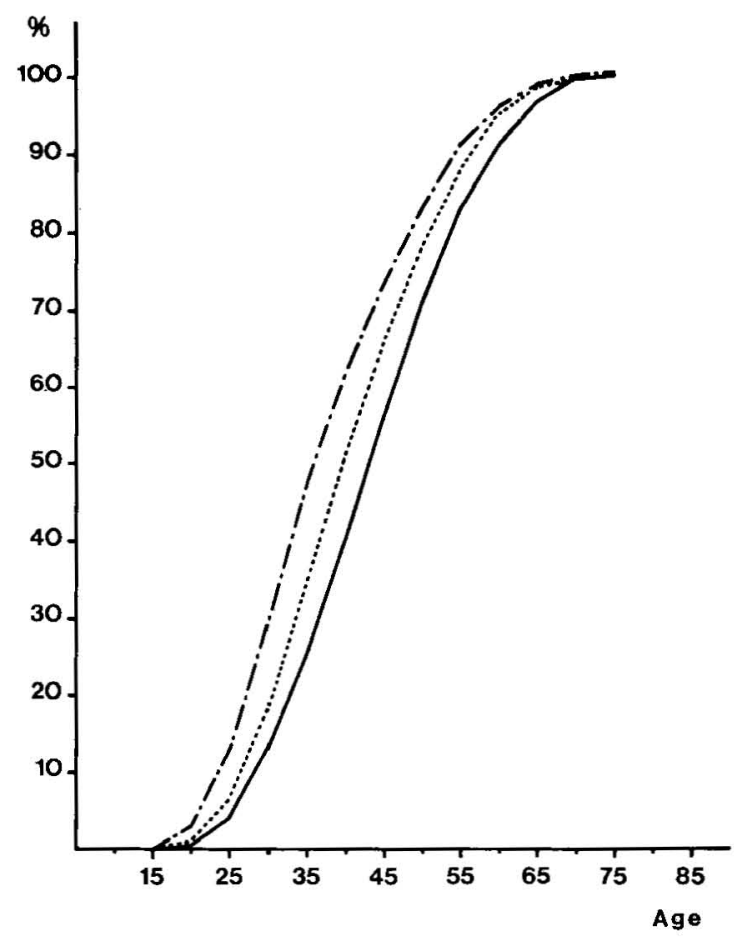

Figure 1. Cumulative frequency distribution of the person-years accumulated in the three subcohorts with different exposure by attained age (five-year categories). (- exposed to formaldehyde, . - . - exposure other than formaldehyde, .... exposure unknown)

Table 3. Mortality of workers producing resins by selected causes in comparison with national and local reference rates. (SMR $=$ observed : expected ratio $\times 100$, standardized by age and calendar year; $95 \% \mathrm{Cl}=95 \%$ confidence interval)

\begin{tabular}{|c|c|c|c|c|c|c|c|}
\hline \multirow[b]{2}{*}{ Cause of deatha } & \multirow{2}{*}{$\begin{array}{l}\text { Deaths } \\
\text { observed }\end{array}$} & \multicolumn{3}{|c|}{ National reference } & \multicolumn{3}{|c|}{ Local reference } \\
\hline & & $\begin{array}{l}\text { Deaths } \\
\text { expected }\end{array}$ & SMR & $95 \% \mathrm{Cl}$ & $\begin{array}{l}\text { Deaths } \\
\text { expected }\end{array}$ & SMR & $95 \% \mathrm{Cl}$ \\
\hline All causes & 112 & 103.70 & 108 & $89-130$ & 124.44 & 92 & $76-111$ \\
\hline $\begin{array}{l}\text { All cancers } \\
(140-209)\end{array}$ & 42 & 27.27 & $154^{*}$ & $111-208$ & 39.72 & 106 & $76-143$ \\
\hline $\begin{array}{l}\text { Cancer of the alimentary tract } \\
(150-159)\end{array}$ & 14 & 8.97 & 156 & $85-262$ & 13.34 & 105 & $57-176$ \\
\hline $\begin{array}{l}\text { Cancer of the esophagus and } \\
\text { stomach } \\
(150-151)\end{array}$ & 7 & 4.73 & 148 & $59-305$ & 7.53 & 93 & $37-192$ \\
\hline $\begin{array}{l}\text { Cancer of the lung } \\
\text { (162) }\end{array}$ & 18 & 7.63 & $236^{*}$ & $140-373$ & 9.70 & $186^{\star}$ & $110-293$ \\
\hline $\begin{array}{l}\text { Hematologic neoplasms } \\
(200-209)\end{array}$ & 5 & 2.49 & 201 & $59-427$ & 3.25 & 154 & $50-359$ \\
\hline $\begin{array}{l}\text { Cardiovascular disease } \\
(390-458)\end{array}$ & 24 & 33.33 & 72 & $46-107$ & 39.34 & $61^{*}$ & $39-91$ \\
\hline $\begin{array}{l}\text { Respiratory disease } \\
(460-519)\end{array}$ & 6 & 6.19 & 97 & $35-211$ & 5.36 & 112 & $41-244$ \\
\hline $\begin{array}{l}\text { Digestive tract disease } \\
(520-579)\end{array}$ & 7 & 11.48 & 61 & $24-126$ & 12.28 & 57 & $23-118$ \\
\hline $\begin{array}{l}\text { External causes } \\
(800-999)\end{array}$ & 17 & 14.66 & 116 & $68-186$ & 12.23 & 139 & $81-223$ \\
\hline
\end{tabular}

a Code of the International Classification of Diseases, eighth revision, in parentheses.

* $p<0.05$. 
pectations. Deaths due to cancer (all sites) were significantly higher than expected only in comparison with the national rates. Among cancers of specific sites, the 18 lung cancer deaths observed made up a significant excess above expectations from either reference population. Hematologic neoplasms were from 1.5 to 2.0 times more numerous than expected, but the increase was not statistically significant. The suggestion of an

Table 4. Mortality from selected cancer causes in the entire cohort according to years elapsed since the beginning of employment. Expected deaths calculated from local rates. $(\mathrm{O}=$ observed number, $\mathrm{E}=$ expected number, $\mathrm{SMR}=$ standardized mortality ratio)

\begin{tabular}{|c|c|c|c|c|c|c|c|c|c|c|c|c|}
\hline \multirow{3}{*}{$\begin{array}{l}\text { Cause of } \\
\text { death }\end{array}$} & \multicolumn{12}{|c|}{ Years since first employment } \\
\hline & \multicolumn{3}{|c|}{$\leq 4$} & \multicolumn{3}{|c|}{$5-9$} & \multicolumn{3}{|c|}{$10-14$} & \multicolumn{3}{|c|}{$\geq 15$} \\
\hline & 0 & $E$ & SMR & 0 & $E$ & SMR & $\mathrm{O}$ & $E$ & SMR & 0 & $E$ & SMR \\
\hline All cancers & 6 & 6.14 & 98 & 11 & 9.06 & 121 & 13 & 11.65 & 112 & 12 & 12.88 & 93 \\
\hline $\begin{array}{l}\text { Cancer of the } \\
\text { alimentary tract }\end{array}$ & 2 & 2.03 & 98 & 6 & 3.06 & 196 & 3 & 3.88 & 77 & 3 & 4.36 & 69 \\
\hline Cancer of the lung & 2 & 1.33 & 151 & 4 & 2.08 & 192 & 6 & 3.00 & 200 & 6 & 3.30 & 182 \\
\hline
\end{tabular}

Table 5. Mortality from selected cancer causes in the entire cohort according to length of employment. Expected number of deaths $(E)$ calculated from local rates. $(\mathrm{O}=$ observed number of deaths, $\mathrm{SMR}=$ standardized mortality ratio)

\begin{tabular}{|c|c|c|c|c|c|c|c|c|c|c|c|c|}
\hline \multirow{3}{*}{$\begin{array}{l}\text { Cause of } \\
\text { death }\end{array}$} & \multicolumn{12}{|c|}{ Length of employment (years) } \\
\hline & \multicolumn{3}{|c|}{$\leq 4$} & \multicolumn{3}{|c|}{$5-9$} & \multicolumn{3}{|c|}{$10-14$} & \multicolumn{3}{|c|}{$\geq 15$} \\
\hline & 0 & $E$ & SMR & $\mathrm{O}$ & $E$ & SMR & $\mathrm{O}$ & $E$ & SMR & 0 & $E$ & SMR \\
\hline All cancers & 26 & 21.42 & 121 & 11 & 8.44 & 130 & 4 & 6.13 & 65 & 1 & 3.73 & 27 \\
\hline $\begin{array}{l}\text { Cancer of the } \\
\text { alimentary tract }\end{array}$ & 7 & 7.08 & 98 & 4 & 2.88 & 139 & 3 & 2.12 & 142 & - & 1.26 & 0 \\
\hline Cancer of the lung & 11 & 5.16 & $213^{a}$ & 5 & 2.04 & 245 & 1 & 1.53 & 65 & 1 & 0.97 & 103 \\
\hline
\end{tabular}

Table 6. Mortality from selected cancer causes in the subcohorts with different exposure (total number of person-years of observation in each subcohort in parentheses). Expected number of deaths (E) calculated from local rates. $(O=$ observed number of deaths, SMR = standardized mortality ratio)

\begin{tabular}{|c|c|c|c|c|c|c|c|c|c|}
\hline \multirow{3}{*}{ Cause of death } & \multicolumn{9}{|c|}{ Exposure } \\
\hline & \multicolumn{3}{|c|}{$\begin{array}{l}\text { Formaldehyde } \\
\qquad(5731)\end{array}$} & \multicolumn{3}{|c|}{$\begin{array}{c}\text { Other } \\
(10527)\end{array}$} & \multicolumn{3}{|c|}{$\begin{array}{l}\text { Unknown } \\
(4078)\end{array}$} \\
\hline & 0 & $E$ & SMR & $\mathrm{O}$ & $\mathrm{E}$ & SMR & 0 & $E$ & SMR \\
\hline All cancers & 19 & 14.89 & 128 & 9 & 16.12 & 54 & 14 & 8.03 & 174 \\
\hline Cancer of the alimentary tract & 8 & 5.18 & 155 & 1 & 5.46 & 18 & 5 & 2.67 & 187 \\
\hline Cancer of esophagus and stomach & 4 & 3.00 & 133 & - & 3.07 & 0 & 3 & 1.49 & 200 \\
\hline Cancer of the lung & 5 & 3.66 & 136 & 6 & 4.06 & 148 & 7 & 1.95 & $358^{a}$ \\
\hline Hematologic neoplasms & 3 & 1.11 & 273 & 1 & 1.49 & 67 & 1 & 0.67 & 143 \\
\hline
\end{tabular}

a $95 \%$ confidence interval $=148-759$.

Table 7. Mortality from selected cancer causes in the subcohort of workers exposed to formaldehyde according to years elapsed since first exposure. Expected number of deaths (E) calculated from local rates. $(O=$ observed number of deaths, SMR = standardized mortality ratio)

\begin{tabular}{|c|c|c|c|c|c|c|c|c|c|c|c|c|}
\hline \multirow{3}{*}{$\begin{array}{l}\text { Cause of } \\
\text { death }\end{array}$} & \multicolumn{12}{|c|}{ Years since first exposure } \\
\hline & \multicolumn{3}{|c|}{$\leq 4$} & \multicolumn{3}{|c|}{$5-9$} & \multicolumn{3}{|c|}{$10-14$} & \multicolumn{3}{|c|}{$\geq 15$} \\
\hline & 0 & $E$ & SMR & o & $E$ & SMR & 0 & $E$ & SMR & $\mathrm{O}$ & $E$ & SMR \\
\hline All cancers & 3 & 2.05 & 146 & 5 & 2.98 & 168 & 5 & 3.83 & 131 & 6 & 6.03 & 100 \\
\hline $\begin{array}{l}\text { Cancer of the } \\
\text { alimentary tract }\end{array}$ & 1 & 0.70 & 144 & 4 & 1.07 & $374^{a}$ & 1 & 1.36 & 74 & 2 & 2.05 & 97 \\
\hline Cancer of the lung & 1 & 0.49 & 203 & 1 & 0.65 & 154 & 1 & 0.97 & 103 & 2 & 1.55 & 129 \\
\hline
\end{tabular}

a $95 \%$ confidence interval $=101-957$. 
Table 8. Mortality from selected cancer causes in the subcohort of workers exposed to formaldehyde according to length of exposure. Expected number of deaths $\langle E)$ calculated from local rates. $(O=$ observed number of deaths, $S M R=$ standardized mortality ratio)

\begin{tabular}{|c|c|c|c|c|c|c|c|c|c|c|c|c|}
\hline \multirow{3}{*}{$\begin{array}{l}\text { Cause of } \\
\text { death }\end{array}$} & \multicolumn{12}{|c|}{ Length of employment (years) } \\
\hline & \multicolumn{3}{|c|}{$\leq 4$} & \multicolumn{3}{|c|}{$5-9$} & \multicolumn{3}{|c|}{$10-14$} & \multicolumn{3}{|c|}{$\geq 15$} \\
\hline & 0 & E & SMR & 0 & E & SMR & $\mathrm{O}$ & $E$ & SMR & O & $\mathrm{E}$ & SMR \\
\hline All cancers & 8 & 7.20 & 111 & 8 & 3.76 & 213 & 2 & 2.32 & 86 & 1 & 1.61 & 62 \\
\hline $\begin{array}{l}\text { Gancer of the } \\
\text { alimentary tract }\end{array}$ & 2 & 2.47 & 81 & 4 & 1.32 & 304 & 2 & 0.83 & 241 & - & 0.57 & 0 \\
\hline Cancer of the lung & 2 & 1.77 & 113 & 2 & 0.92 & 217 & - & 0.56 & 0 & 1 & 0.41 & 247 \\
\hline
\end{tabular}

increased mortality from cancer of the alimentary tract resulting from the comparison with the national rates disappeared when the observed deaths were compared with deaths expected from the local population rates. Deaths due to nonmalignant diseases of the cardiovascular and alimentary systems were fewer than expected. Mortality from respiratory diseases was similar to both the national and local expected figures. Mortality from external causes (accidents, violence, etc) was slightly increased above expectations.

Table 4 presents the results of the analysis by year since first exposure for selected cancer causes. No definite trends were visible according to the increasing number of years since the beginning of exposure (latency); in particular, the increased lung cancer mortality seemed to be evenly distributed across the categories. Analysis by length of employment in the plant (table 5) showed a higher than expected mortality from all cancers and cancer of the lung in the categories of shortest duration. A weak suggestion of a risk increasing with duration of employment was obtained for cancers of the alimentary tract.

The cohort was then split into exposure categories. The results of the analysis regarding these categories and selected cancer sites are reported in table 6 . The SMR values of the workers known to have been exposed to formaldehyde were consistently elevated, but none of them significantly. Workers exposed to chemicals other than formaldehyde in the plant experienced a cancer mortality lower than expected, with the sole exception of lung cancer. Workers whose exposure could not be ascertained exhibited the most elevated risk of dying from cancer, and the increased SMR for lung cancer turned out to be statistically significant. As already mentioned, the person-years distribution in the groups seemed to allow the comparison of their SMR values. If we ignore, for the moment, workers with unknown exposure, it is apparent that formaldehyde workers experienced an all cancer mortality more than twice as high as that of the workers with other types of exposure. This increase was mainly due to digestive cancer and hematologic neoplasms. There was no difference, instead, between the two groups with regard to lung cancer mortality. The ratio of the "directly" standardized (standard = total cohort) mortality rates (SRR) was also calculated in
Table 9. Mortality from selected cancer causes in the subcohorts composed under the alternative assumption that all workers with unknown exposure had actually been exposed to formaldehyde (formaldehyde plus unknown) or that they all had had other exposure (other plus unknown).

\begin{tabular}{|c|c|c|c|c|c|c|}
\hline \multirow{2}{*}{ Cause of death } & \multicolumn{3}{|c|}{$\begin{array}{l}\text { Formaldehyde } \\
\text { plus unknown }\end{array}$} & \multicolumn{3}{|c|}{$\begin{array}{l}\text { Other plus } \\
\text { unknown }\end{array}$} \\
\hline & 0 & $E$ & SMR & 0 & $E$ & SMR \\
\hline All cancers & 33 & 22.4 & 144 & 23 & 24.7 & 93 \\
\hline $\begin{array}{l}\text { Cancer of the } \\
\text { alimentary tract }\end{array}$ & 13 & 7.8 & 166 & 6 & 8.1 & 74 \\
\hline Cancer of the lung & 12 & 5.6 & $214^{a}$ & 13 & 6.0 & $216^{\mathrm{b}}$ \\
\hline $\begin{array}{l}\text { Hematologic } \\
\text { neoplasms }\end{array}$ & 4 & 1.8 & 222 & 2 & 2.17 & 92 \\
\hline
\end{tabular}

a $95 \%$ confidence interval $=111-374$.

b $95 \%$ confidence interval $=115-371$.

order to compare workers exposed to formaldehyde with those with other exposure, and the results previously obtained through the SMR comparison were, in essence, confirmed. Significantly increased ratios were obtained for all cancer [SRR 2.1; $95 \%$ confidence interval $(95 \% \mathrm{CI}) 1.29-3.28]$ and for cancer of the alimentary tract (SRR $=3.5,95 \% \mathrm{CI}=1.38-$ 8.89); the SRR for other cancer deaths did not, instead, depart significantly from unity.

Further analysis was carried out on the subcohort of formaldehyde-exposed workers. Results by years since first exposure are shown in table 7. Admittedly, with the low number of observed deaths, if a pattern is discernible, it is a decreasing one with increasing time since the beginning of exposure. Even analysis by duration of exposure (table 8) failed to reveal any definite pattern or trend; again, the numbers were small.

In the analysis stage, an attempt was made to overcome the bias due to the lack of information on the exposure history of a number of workers by making "extreme" assumptions, ie, that all workers with unknown exposure had in fact or, alternatively, had not been exposed to formaldehyde. The results of this analysis are shown in table 9 . As expected, attributing all workers with unknown exposure to the subcohort of workers exposed to formaldehyde produced a further increase in the SMR values of this group. (For comparison see table 6.) And the excess risk from lung 
cancer reached statistical significance. The addition of these workers to the subcohort with "other" exposure produced an analogous increase of the relevant risk estimates with no change, however, in the direction (above or below 100) of the SMR values. (See table 6.) Even in this exposure group, under this assumption, the increased lung cancer risk became statistically significant.

\section{Discussion}

During the study period the examined cohort of resins production workers experienced a lung cancer mortality significantly higher than expected, in comparison either with the national population of the same sex and birth cohort or with the local one. The comparison with the local rates makes it unlikely that personal habits or environmental or sociocultural factors could explain the increased risk noted. On the other hand, no definite association of the increased lung cancer risk with either duration of employment or years since first employment in the factory was found.

An excessive number of deaths from cancer of the alimentary tract and from hematologic neoplasms was also noted in the entire cohort. However, the SMR values were not statistically significant, and the excesses became very modest or disappeared when the expected deaths were calculated from local rates. The analysis by latency and duration of employment failed to suggest an association between employment in the plant and an increased risk from such types of cancer.

No cases of nasal cancer were recorded on the death certificates; the expected figure was extremely low however ( 0.0327 expected).

Exposure in the plant was, as mentioned, complex, and the available exposure histories were not complete or exhaustive. It was, nonetheless, possible to identify workers who had held only jobs with exposure to formaldehyde. The comparison of the mortality of this subcohort with the local rates suggested an increased risk from cancer (all sites), cancer of the alimentary tract, lung cancer, and hematologic neoplasms. The increased SMR values were not however statistically significant, nor did the analysis by duration of exposure to formaldehyde and latency reveal clear-cut trends. Scanty significant results were obtained, but they could well be explained by chance alone, given the high number of comparisons performed.

The internal comparison of the formaldehydeexposed workers against the workers in the same plant with known exposure of other types showed no difference in lung cancer mortality, while mortality from cancer (all sites) and from digestive cancer was significantly higher among the formaldehyde-exposed workers. An elevated risk ratio was also noted for hematologic neoplasms. It should be mentioned that the very low number of observed deaths makes the estimates of the "directly" standardized mortality rates unstable. In addition the comparison of workers exposed to formaldehyde with workers with other exposure was certainly affected by the information bias due to the lack of detailed work histories for a number of former employees.

The assumption that workers with unknown exposure had actually been exposed to formaldehyde or, alternatively, to other compounds did not provide any definite clue to the interpretation of the results. In fact, a significantly elevated risk from lung cancer was obtained in both exposure groups after the workers with unknown exposure were added. Instead, under the conservative assumption that they all had not been exposed to formaldehyde, one could derive the suggestion of an association of digestive and hematologic malignancies with formaldehyde exposure. (Compare the SMR values in the subcohort of formaldehyde-exposed employees in table 6 with those of the subcohort composed of workers with other plus unknown exposure in table 9.) However such a suggestion is not supported by any other result of our study.

Among the epidemiologic studies so far published, only one, carried out on British chemical workers, provided a very weak suggestion of a possibly increased lung cancer risk (1), but its relationship with formaldehyde exposure turned out to be highly improbable after thorough analysis (2). Other studies suggested an elevation of the cancer risk of the upper respiratory tract in several occupational cohorts with a potential for exposure to formaldehyde $(14,17,20)$, but none could draw definite conclusions about the specificity of the association. As regards cancer of other sites, an increased risk of cancer of the alimentary tract was suggested by epidemiologic studies of embalmers (22), chemical workers $(14,16)$, and permanent-press garment workers (20); and the risk of hematologic neoplasms was elevated in two investigations $(8,20)$. All these studies suffered from limitations such as confounding by other exposure, small sample size, etc. The interpretation of these findings is further hindered by the lack of a biologically plausible explanation of the effect of formaldehyde on these body sites, while a sound hypothesis exists for the possible carcinogenic effect of formaldehyde on the upper respiratory tract (21). Other studies failed to reveal any increased risk of cancer $(4,11,13,18)$. Despite their different design, all the studies were affected by limitations such as mixed exposure, short latency, low statistical power, short duration of exposure or observation period, and so on. Thus, despite their being "negative," they were not able to demonstrate conclusively that an increased cancer risk from formaldehyde exposure did not actually exist.

Our study evidenced a significantly increased risk of lung cancer in a plant with multiple exposures, where concentrations of formaldehyde above 3.0 $\mathrm{mg} / \mathrm{m}^{3}$ were not infrequent, particularly in the past. However, no sufficient evidence emerged, either from the external or from the internal comparison per- 
formed, capable of specifically associating the excessive lung cancer risk observed with exposure to formaldehyde. The lung cancer excess observed in the entire cohort stemmed mainly from the mortality experience of workers with unknown exposure, who, as a group, exhibited a rather elevated risk from any of the relevant causes of death. This phenomenon could be a reflection of the selective feature of their being short-term employees $(90 \%$ of the person-years accumulated by this subcohort was in the employment duration category of $<5$ years) rather than a consequence of their specific, although not ascertained, exposure. The interpretation of the rather modestly increased risk of digestive cancer and hematologic neoplasms remained inconclusive, although suggestions emerged of its possible association with formaldehyde exposure. Thus, even in our study, the small number of deaths from some of the relevant causes, the approximate quantification and loose categorization of the individual exposure histories, along with a possibly still limited length of the follow-up period, prevented any firm conclusion from being drawn about the hypothesis tested.

Finally, a few comments regarding other possibly relevant exposures in the plant. - Long-term health effects possibly linked to styrene and epichlorohydrin were not investigated for several reasons, the major ones being the specific hypothesis of this study and the limited number of workers exposed to these compounds. The very low job mobility of the formaldehyde workers renders it improbable that these compounds caused an appreciable confounding effect in the results presented and discussed. It should be mentioned that the results for workers with exposure other than formaldehyde did actually suggest a moderately increased risk from lung cancer (table 6), but too many different jobs, and hence different exposures, were included in this category to allow any hypothesis to be drawn from the findings regarding styrene or epichlorohydrin effects.

The study is now continuing by means of an extension of the follow-up period and a search for more detailed and exhaustive information on individual exposures. Since several independent studies are still under way in different countries, we trust that in a few years their results will concur in clarifying the possible carcinogenic risk, if any, posed by formaldehyde to man under certain exposure conditions.

\section{Acknowledgments}

We wish to thank the management and the union of the plant where the study was carried out for having prompted this investigation and for their cooperation in its conduction. The plant medical service provided valuable assistance, and the help we received from $\mathrm{Dr}$ $\mathrm{S}$ Tenca is gratefully acknowledged. We are indebted to Mr E Radice for his skillful technical assistance.

\section{References}

1. Acheson ED, Barnes HR, Gardner MJ, Osmond C, Pannett B, Taylor CP. Formaldehyde in the British chemical industry: An occupational cohort study. Lancet 1 (1984) $611-616$.

2. Acheson ED, Barnes HR, Gardner MJ, Osmond C, Pannett B, Taylor CP. Formaldehyde process workers and lung cancer. Lancet 1 (1984) 1066-1067.

3. Albert RE, Sellakumar AR, Laskin S, Kuschner M, Nelson N, Snyder CA. Gaseous formaldehyde and hydrogen chloride induction of nasal cancer in the rat. J Natl Cancer Inst 68 (1982)

4. Fayerweather WE, Pell S, Bender JR. Case control study on cancer deaths in Du Pont workers with potential exposure to formaldehyde. In: Clary JJ, Gibson JE, Waritz RS, ed. Formaldehyde - Toxicology, epidemiology, mechanisms. Marcel Dekker Inc, New York, NY 1983, pp 47-113.

5. Gamble J. Effects of formaldehyde on the respiratory system. In: Gibson JE, ed. Formaldehyde toxicity. Hemisphere \& McGraw Hill, Washington, DC 1983, pp 175-197.

6. Halperin WE, Goodman M, Stayner L, Elliott LJ, Keenlynde RA, Landrigan PJ. Nasal cancer in a worker exposed to formaldehyde. J Am Med Assoc 249 (1983) $510-512$.

7. Harrington JM, Oakes D. Mortality study of British pathologists 1974-1980. Br J Ind Med 41 (1984) 188-191.

8. Harrington JM, Shannon HS. Mortality study of pathologists and medical laboratory technicians. Br Med J 4 (1975) 329-332.

9. International Agency for Research on Cancer. Formaldehyde. Lyon 1983, pp 345-389. (IARC monographs on the evaluation of the carcinogenic risk of chemicals to humans, number 29).

10. Jensen OM. Cancer risk from formaldehyde. Lancet 2 (1980) 480-481.

11. Jensen OM, Andersen SK. Lung cancer risk from formaldehyde. Lancet 1 (1982) 913.

12. Kerns WD, Pavkov KL, Donofrio DJ, Gralla EJ, Swenberg JA. Carcinogenicity of formaldehyde in rats and mice after long-term inhalation exposure. Cancer Res 43 (1983) 4382-4392.

13. Levine RJ, Andjelkovich DA, Shaw LK. The mortality of Ontario undertakers and a review of formaldehyderelated mortality studies. J Occup Med 26 (1984) $740-746$.

14. Liebling $T$, Rosenman KD, Pastides $H$, Griffin RG, Lemeshow S. Cancer mortality among workers exposed to formaldehyde. Am J Ind Med 5 (1984) 423-428.

15. Maibach H. Formaldehyde: Effects on animal and human skin. In: Gibson JE, ed. Formaldehyde toxicity. Hemisphere \& McGraw Hill, Washington, DC 1983, pp $166-174$.

16. Marsh GM. Proportional mortality patterns among chemical plant workers exposed to formaldehyde. $\mathrm{Br} \mathrm{J}$ Ind Med 39 (1982) 313-322.

17. Olsen JH, Plough Jensen S, Hink M, Faurbo K, Breum NO, Jensen OM. Occupational formaldehyde exposure and increased nasal cancer risk in man. Int J Cancer 34 (1984) 639-644.

18. Partanen $T$, Kauppinen T, Nurminen M, Nickels J, Hernberg S, Hakulinen T, Pukkala E, Savonen E. Formaldehyde exposure and respiratory and related cancers: A case-referent study among Finnish woodworkers. Scand J Work Environ Health 11 (1985) 409-415.

19. Rothman KJ, Boice JD Jr. Epidemiologic analysis with a programmable calculator. Epidemiologic Resources, Inc, Boston, MA 1982, pp 30-31.

20. Stayner L, Smith AB, Reeve G, Blade L, Elliott L, Keenlyside R, Halperin W. Proportionate mortality study of workers in the garment industry exposed to 
formaldehyde. Am J Ind Med 7 (1985) 229-240.

21. Swenberg JA, Gross EA, Martin J, Popp JA. Mechanism of formaldehyde toxicity. In: Gibson JE, ed. Formaldehyde toxicity. Hemisphere \& McGraw-Hill, Washington, DC 1983, pp 132-147.

22. Walrath J, Fraumeni JF. Mortality pattern among embalmers. Int J Cancer 31 (1983) 407-411.

23. Wong $\mathrm{O}$. An epidemiologic mortality study of a cohort of chemical workers potentially exposed to formalde- hyde, with a discussion on SMR and PMR. In: Gibson JE, ed. Formaldehyde toxicity. Hemisphere \& McGrawHill, Washington, DC 1983, pp 256-272.

24. Zocchetti C, Bertazzi PA. Un programma computerizzato per l'analisi degli studi coorte di mortalita' negli ambienti di lavoro. Med Lav 73 (1982) 9-21.

Received for publication 11 February 1986 